\title{
Influence of Mifepristone in Induction Time for Terminations in the Second and Third Trimester
}

\author{
Einfluss von Mifepriston auf die Einleitungszeit \\ bei Schwangerschaftsabbrüchen im 2. und 3. Trimenon
}

Authors

Affiliation
M. Hoopmann, J. Hirneth, J. Pauluschke-Fröhlich, B. Yazdi, H. Abele, D. Wallwiener, K. O. Kagan

Department of Obstetrics and Gynaecology, University of Tübingen, Tübingen

\author{
Key words \\ - mifepristone \\ - misoprostol \\ - gemeprost \\ - dinoprostone \\ - termination

\section{Schlüsselwörter} \\ - Mifepriston \\ - Misoprostol \\ - Gemeprost \\ - Dinoproston \\ - Schwangerschaftsabbruch
}

Deutschsprachige Zusatzinformationen online abrufbar unter: www.thieme-connect.de/ ejournals/toc/gebfra received 4.11.2013

revised 19.12.2013

accepted 14.1.2014

Bibliography

Dol http://dx.doi.org/

10.1055/s-0033-1360361

Published online 28.3.2014

Geburtsh Frauenheilk 2014; 74 :

350-354 ๑ Georg Thieme

Verlag KG Stuttgart · New York . ISSN 0016-5751

\section{Correspondence}

\section{Prof. Dr. Karl Oliver Kagan}

University of Tübingen

Department of Obstetrics

and Gynaecology

Calwerstraße 7

72076 Tübingen

KOKagan@gmx.de

\section{Abstract}

Termination of pregnancy after the first trimester is generally carried out by medical induction.

Question: The aim of this study is to investigate the effect of mifepristone before administration of the prostaglandin derivative on induction time. Material and Methods: We analysed 333 medically indicated terminations after the first trimester under the terms of $\S 218$ a Para. 2 of the German Criminal Code, in which the prostaglandin derivatives misoprostol, gemeprost or dinoprostone were administered with or without pretreatment with $600 \mathrm{mg}$ of mifepristone. The time interval between the initial administration of prostaglandin and delivery was investigated. Using uni- and multivariate regression analysis, the effect of maternal age, body mass index, gravidity and parity, previous Caesarean sections, gestational age and the induction regimen on the induction time were analysed.

Results: The average induction time was significantly shortened with mifepristone (15.1 \pm 11.9 hours with mifepristone vs. $25.3 \pm 24.2$ hours without mifepristone [ $<<0.001]$ ). The combination of mifepristone and misoprostol was most frequently used and proved to be the most effective regimen, reducing the induction period to $13.6 \pm 10.3$ hours. Besides pre-treatment with mifepristone, gestational age and a history of delivery without Caesarean section were significant influencing factors in reducing the induction time.

Conclusion: The induction interval can be significantly shortened by the prior administration of mifepristone. The combination of mifepristone and misoprostol or gemeprost is the most effective regimen for the medical termination of pregnancy.

\section{Zusammenfassung \\ $\nabla$}

Fragestellung: Schwangerschaftsabbrüche nach dem 1. Trimenon erfolgen in der Regel medikamentös. Ziel der Arbeit ist es, den Einfluss von Mifepriston vor der eigentlichen Prostaglandinderivatgabe auf die Einleitungszeit zu untersuchen.

Material und Methodik: Ausgewertet wurden 333 Schwangerschaftsabbrüche mit medizinischer Indikation gemäß §218a Abs. 2 StGB nach dem 1. Trimenon, bei denen die Prostaglandinderivate Misoprostol, Gemeprost oder Dinoproston mit oder ohne Vorbehandlung mit $600 \mathrm{mg}$ Mifepriston zum Einsatz kamen. Untersucht wurde das Zeitintervall zwischen 1. Prostaglandinapplikation und Entbindung. In einer uni- und multivariaten Regressionsanalyse wurden die Faktoren mütterliches Alter, Body-Mass-Index, Gravidität und Parität, Z.n. Sectio caesarea, das Gestationsalter sowie das Einleitungsregime auf ihren Einfluss auf die Einleitungszeit analysiert.

Ergebnisse: Mit Mifepriston verkürzte sich das mittlere Einleitungsintervall signifikant auf 15,1 $( \pm 11,9)$ Stunden im Vergleich zu 25,3 $( \pm 24,4)$ Stunden ohne Mifepriston ( $\mathrm{p}<0,001)$. Die Kombination mit Mifepriston und Misoprostol war das am häufigsten angewandte Regime mit einer Verkürzung der Einleitungszeit auf 13,6 \pm 10,3 Stunden. Neben der Vorbehandlung mit Mifepriston waren das Gestationsalter und der Z.n. Entbindung ohne Sectio signifikante Einflussfaktoren für eine Verkürzung der Einleitungszeit.

Schlussfolgerung: Das Einleitungsintervall konnte durch die vorangehende Gabe von Mifepriston signifikant verkürzt werden. Die Kombination aus Mifepriston und Misoprostol stellt ein effektives Medikamentenregime für einen Schwangerschaftsabbruch nach dem 1 . Trimester dar. 


\section{Introduction}

\section{$\nabla$}

Termination of pregnancy is one of the most common surgical procedures in gynaecology and obstetrics. Each year, 50 million terminations are registered worldwide [1]. According to data from the Federal Statistical Office, almost 107000 terminations were carried out in Germany in 2012 [2]. The majority of these were performed surgically using curettage or vacuum aspiration. However, around $10-15 \%$ of the terminations were carried out after the end of the first trimester, and medical termination was the preferred method $[3,4]$. The higher morbidity and maternal mortality rates of pregnancy terminations after the first trimester should be especially considered [5]. In a study carried out in the USA, Bartlett et al. showed that the mortality rate of terminations was 0.7 per 100000 , and that this increased by $38 \%$ with each week of pregnancy [5].

The prostaglandin derivatives misoprostol, gemeprost and dinoprostone are primarily used for medically-induced terminations. These substances exhibit a satisfactory level of safety and efficacy for cervical ripening, induction of labour and medical abortion [6, 7]. In a previous study by our working group, we observed that $90 \%$ of pregnancy terminations occurred within 24 hours of the start of prostaglandin administration [8]. Consistent with other study groups, gestational age and parity were shown to be decisive influencing factors [9].

To shorten the induction time of pregnancy terminations, mifepristone can also be administered before the prostaglandin [7]. As a result of its anti-progestogenic effect as a competitive inhibitor of the progesterone receptor, mifepristone reduces the uterine contraction threshold and promotes cervical ripening. Mifepristone is licensed for the medical termination of pregnancy up to the 49th day of amenorrhoea in sequential use with a prostaglandin. However, the combination can also be used in more advanced weeks of pregnancy [10].

The aim of this retrospective study is to investigate the effectiveness of the combination of mifepristone with various different prostaglandin derivatives with regard to the induction interval, and to identify factors which influence the duration of induction.

\section{Materials and Methods}

In this retrospective study, all abortions carried out at the University Hospital for Women in Tuebingen between 2005 and 2012 in which prostaglandins were administered to terminate the pregnancy were evaluated. The termination had to be carried out according to §219a Para 2. of the German Criminal Code (StGB). Terminations carried out after the legal termination period (§ 218a Para 1. StGB) were not included. Fetocide was performed in the event of non-lethal abnormalities after 24 completed weeks of pregnancy.

Either misoprostol (Cytotec ${ }^{\circledR} 200 \mu \mathrm{g}$ vaginally and $200 \mu \mathrm{g}$ orally), gemeprost (Cergem ${ }^{\circledR} 1 \mathrm{mg}$ vaginally) or dinoprostone (Miniprostin $\mathrm{Gel}^{\circledR} 2 \mathrm{mg}$ vaginally) were used for induction. Prostaglandin administration was repeated at four to six hourly intervals until regular contractions were observed. Patients who had a previous history of Caesarean section received either dinoprostone or gemeprost. The induction was otherwise carried out using misoprostol or gemeprost.

The drug regimen used was chosen by the responsible gynaecologists. Since 2009, the progesterone receptor antagonist mife- pristone (Mifegyne ${ }^{\circledR} 600 \mathrm{mg}$ orally) has been administered 24 to 48 hours before the initial dose of prostaglandin.

All patients were informed about the off-label use of the drugs and gave their consent for the procedure.

Partial results from 184 of the 333 pregnancy terminations evaluated in this study were published in 2011 [8]. However, this study did not describe the cases where mifepristone was administered first.

\section{Statistical evaluation}

The maternal age (years), body mass index $\left(\mathrm{kg} / \mathrm{m}^{2}\right)$, gravidity and parity (number of each), previous Caesarean section (yes/no), previous vaginal deliveries (yes/no) and gestational age (weeks of pregnancy) were recorded in a digital database for each patient.

In our previous study, we were able to show that observed abnormalities (aneuploidy, heart defects, non-immune hydrops fetalis, neural tube defects, neuromuscular or skeletal abnormalities, CNS abnormalities and other abnormalities) and changes in the volume of amniotic fluid do not have any effect on the induction period [8]. These parameters were therefore not included in this analysis.

The induction regimen (misoprostol, gemeprost or dinoprostone), previous administration of mifepristone (yes/no) and the induction time (hours), defined as the time interval between the first dose of prostaglandin and cutting of the umbilical cord, were also recorded.

Terminations were excluded from further evaluation if the drug regimen was altered during the course of a termination, if a balloon catheter was inserted, or if the termination ended with a Caesarean section.

Induction times with and without mifepristone were compared using a Student's t-test after normal distribution had been checked using the Kolmogorov-Smirnov test. Significant parameters which influenced induction time were investigated using uni- and multivariant regression analysis. A uni- and multivariate logistic regression analysis was used to determine the significant factors which influenced the delivery within 12 hours after induction.

The level of significance was set at a p-value of 0.05 .

\section{Results \\ $\nabla$}

\section{Patient characteristics}

The study population included 352 pregnancies. 19 (5.4\%) pregnancies were excluded either because they were terminated surgically using suction curettage, because they were terminated by Caesarean section in the case of an advanced gestational age, because the medical induction regimen was altered during the course of the termination, or because a balloon catheter was inserted. A total of 333 pregnancies were therefore available for evaluation.

The median maternal age at induction was 33.0 (interquartile range IQR 28.1-37.0) years, the median gestational age was 18.7 (IQR 15.4-21.6) weeks of pregnancy, the patients' median BMI was 23.8 (IQR 21.5-26.6) $\mathrm{kg} / \mathrm{m}^{2}$, and the median gravidity and parity were 2 (IQR 1-3) and 1 (IQR 0-1) respectively. A Caesarean section was performed in 49 of the 177 patients with a history of previous delivery. The observed fetal abnormalities are listed in - Table 1. 
$242(72.7 \%)$ of pregnancies were terminated using misoprostol, $66(19.8 \%)$ using gemeprost and 25 (7.5\%) using dinoprostone. 81 (24.3\%) patients initially received mifepristone ( Table 2 ).

\section{Induction times and their influencing factors}

The mean induction time across the whole study group from initial drug administration to delivery was 22.8 (standard deviation \pm 22.4 ) hours. In 123 (36.9\%) patients, a maximum of 12.0 hours elapsed between the first induction and delivery. This was a maximum of 18.0 hours in 190 (57.1\%) patients, and more than 24.0 hours in 235 patients (70.6\%).

With mifepristone, the average induction interval was reduced significantly to $15.1( \pm 11.9)$ hours compared to $25.3( \pm 24.4)$ hours without mifepristone $(\mathrm{p}<0.001)$ ( $\bullet$ Fig. 1$)$. In the subgroups which were induced with misoprostol (13.6 \pm 10.3 vs. $22.0 \pm 22.1$ hours; $\mathrm{p}<0.001)$, gemeprost $(11.4 \pm 6.5$ vs. $23.6 \pm$ 17.9 hours; $\mathrm{p}<0.001)$ and dinoprostone $(37.6 \pm 11.3$ vs. $61.1 \pm$ 33.4 hours; $p<0.015$ ), the average induction interval was significantly shorter following prior mifepristone administration (๑ Table 2).

- Table 3 shows the results of the uni- and multivariate regression analyses to determine the significant influencing factors on induction time. Inductions in which dinoprostone was administered showed significantly longer induction times. In contrast, the use of mifepristone in combination with a previous history of delivery without Caesarean section led to a significant reduction in the induction time.

Significant influencing parameters on delivery within 12 hours were low gestational age, a history of delivery (deliveries) without Caesarean section and prior mifepristone administration (๑ Table 4).

\section{Discussion}

In the present study, we were able to show that the time interval between induction and delivery in medical abortions can be significantly reduced by the combined use of mifepristone and prostaglandin derivatives. Irrespective of the choice of prostaglandin, a reduction in the induction time by over 10 hours was recorded. In addition to mifepristone administration, early gestational age and higher parity without previous Caesarean section were significant influencing factors which led to a reduction in the induction time.

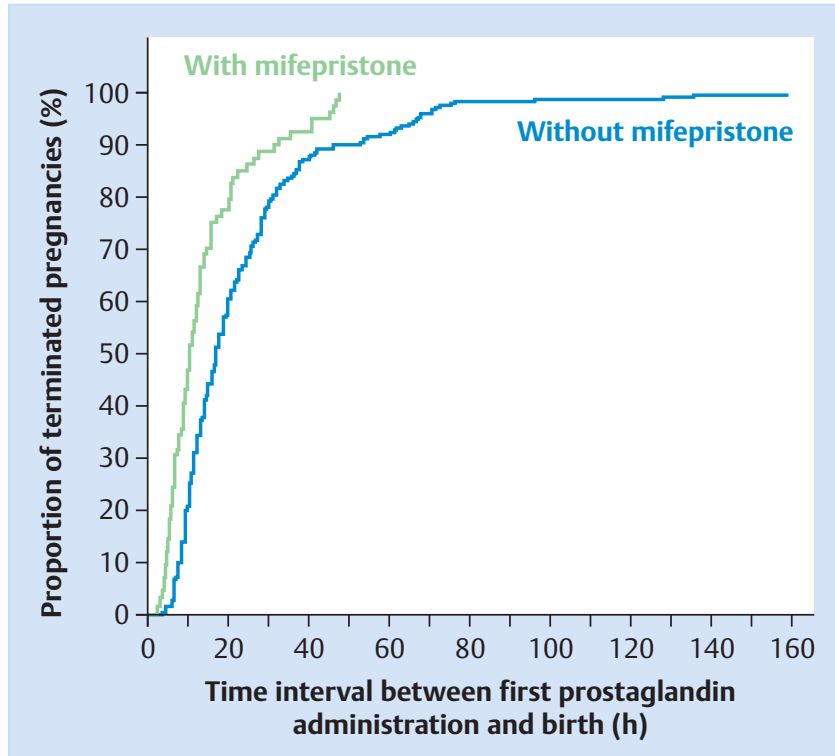

Fig. 1 Time interval between initial prostaglandin administration and birth.

Table 1 Foetal abnormalities observed in the study group.

\begin{tabular}{|lcc|}
\hline Abnormality & n & \% \\
\hline Aneuploidy & 142 & $42.7 \%$ \\
\hline Heart defect & 12 & $3.6 \%$ \\
\hline Non-immunological hydrops fetalis & 18 & $5.4 \%$ \\
\hline Neural tube defect & 25 & $7.5 \%$ \\
\hline Neuromuscular or skeletal abnormality & 38 & $11.4 \%$ \\
\hline Renal abnormality & 27 & $8.1 \%$ \\
\hline CNS abnormality & 29 & $8.7 \%$ \\
\hline Other abnormality & 42 & $12.6 \%$ \\
\hline Total & 333 & $\mathbf{1 0 0} \%$ \\
\hline
\end{tabular}

Our results are partially consistent with previous studies. Using 106 pregnancy terminations, Jannet et al. showed that induction times were significantly shorter in multipara when using a drug regimen similar to our induction regimen [11]. In our previous

Table 2 Induction time between initial prostaglandin administration and birth.

\begin{tabular}{|c|c|c|c|}
\hline \multirow[t]{2}{*}{ Induction protocol } & \multirow[t]{2}{*}{ Number } & \multicolumn{2}{|l|}{ Induction time } \\
\hline & & Mean value (standard deviation) & Median (25-75\% quantile) \\
\hline Misoprostol & 242 & $19.7(19.9)$ & $14.2(10.0-23.0)$ \\
\hline With mifepristone & 67 & $13.6(10.3)^{*}$ & $10.7(6.7-15.5)$ \\
\hline Without mifepristone & 175 & $22.0(22.1)$ & $16.0(11.0-30.0)$ \\
\hline Gemeprost & 66 & $22.1(17.4)$ & $17.7(11.0-30.0)$ \\
\hline With mifepristone & 8 & $11.4(6.5)^{*}$ & $10.1(6.0-15.0)$ \\
\hline Without mifepristone & 58 & $23.6(17.9)$ & $19.9(11.0-30.0)$ \\
\hline Dinoprostone & 25 & $55.5(31.1)$ & $49.0(32.0-69.0)$ \\
\hline With mifepristone & 6 & $37.6(11.3)^{*}$ & $39.1(28.3-48.1)$ \\
\hline - Without mifepristone & 19 & $61.1(33.4)$ & $61.3(32.0-71.3)$ \\
\hline Total & 333 & $22.4(22.4)$ & $16.0(10.0-28.0)$ \\
\hline
\end{tabular}

Difference between induction with misoprostol with mifepristone vs. without mifepristone t-test $p<0.001$

Difference between induction with gemeprost with mifepristone vs. without mifepristone t-test $p=0.001$

Difference between induction with dinoprostone with mifepristone vs. without mifepristone t-test $\mathrm{p}=0.015$ 
Table 3 Uni- and multivariate regression analysis to determine the significant influencing factors on the induction time between initial prostaglandin administration and birth.

\begin{tabular}{|c|c|c|c|c|}
\hline \multirow[t]{3}{*}{ Parameter } & \multicolumn{4}{|l|}{ Induction time } \\
\hline & \multicolumn{2}{|l|}{ Univariate regression } & \multicolumn{2}{|l|}{ Multivariate regression } \\
\hline & OR $[95 \% \mathrm{Cl}]$ & $\mathbf{p}$ & OR $[95 \% \mathrm{Cl}]$ & $\mathbf{p}$ \\
\hline Age (years) & $-0.097(-0.508-0.313)$ & 0.641 & & \\
\hline $\operatorname{BMI}\left(\mathrm{kg} / \mathrm{m}^{2}\right)$ & $0.261(-0.275-0.797)$ & 0.339 & & \\
\hline Gestational age (weeks of pregnancy) & $0.918(0.318-1.519)$ & 0.003 & $0.386(-0.162-0.935)$ & 0.167 \\
\hline Gravidity (n) & $-1.184(-3.059-0.690)$ & 0.215 & & \\
\hline Parity (n) & $-1.336(-3.908-1.236)$ & 0.308 & & \\
\hline \multicolumn{5}{|l|}{ Obstetrics medical history } \\
\hline First-time mother & 1 & & & \\
\hline Previous C-section & $11.748(4.539-18.957)$ & 0.001 & $-4.685(-13.112-3.741)$ & 0.275 \\
\hline - Previous delivery (deliveries) without C-section & $-8.582(-13.695--3.469)$ & 0.001 & $-8.622(-13.338--3.906)$ & $<0.001$ \\
\hline \multicolumn{5}{|l|}{ Mifepristone prior to induction } \\
\hline \multicolumn{5}{|l|}{ No } \\
\hline Ves & $-10.183(-4.643--15.723)$ & $<0.001$ & $-10.052(-15.029--5.074)$ & $<0.001$ \\
\hline \multicolumn{5}{|l|}{ Drug regimen } \\
\hline - Misoprostol & 1 & & & \\
\hline Gemeprost & $2.466(-3.124-8.056)$ & 0.386 & & \\
\hline Dinoprostone & $35.815(27.359-44.272)$ & $<0.001$ & $33.421(22.546-44.296)$ & $<0.001$ \\
\hline
\end{tabular}

Table 4 Uni- and multivariate logistic regression for predicting a delivery within 12 hours of the initial prostaglandin dose.

\begin{tabular}{|c|c|c|c|c|}
\hline \multirow[t]{3}{*}{ Parameter } & \multicolumn{4}{|c|}{ Delivery within 12 hours of first induction } \\
\hline & \multicolumn{2}{|c|}{ Univariate logistic regression } & \multicolumn{2}{|c|}{ Multivariate logistic regression } \\
\hline & OR $[95 \% \mathrm{Cl}]$ & $\mathbf{p}$ & OR $[95 \% \mathrm{Cl}]$ & $\mathbf{p}$ \\
\hline Age (years) & $1.049(1.009-1.090)$ & 0.017 & $1.009(0.962-1.057)$ & 0.717 \\
\hline $\operatorname{BMI}\left(\mathrm{kg} / \mathrm{m}^{2}\right)$ & $0.955(0.906-1.007)$ & 0.086 & & \\
\hline Gestational age (weeks of pregnancy) & $0.885(0.830-0.943)$ & $<0.001$ & $0.886(0.824-0.952)$ & 0.001 \\
\hline Gravidity (n) & $1.340(1.123-1.599)$ & 0.001 & $0.961(0.707-1.305)$ & 0.797 \\
\hline Parity (n) & $1.561(1.216-2.005)$ & $<0.001$ & $1.314(0.896-1.928)$ & 0.162 \\
\hline \multicolumn{5}{|l|}{ Obstetrics medical history } \\
\hline - First-time mother & 1 & & & \\
\hline - Previous C-section & $0.738(0.304-1.790)$ & 0.502 & & \\
\hline - Previous delivery (deliveries) without C-section & $4.147(2.399-7.170)$ & $<0.001$ & $4.875(2.745-8.658)$ & $<0.001$ \\
\hline \multicolumn{5}{|l|}{ Mifepristone prior to induction } \\
\hline No & 1 & & & \\
\hline$\checkmark$ Yes & $2.653(1.589-4.428)$ & $<0.001$ & $3.198(1788-5.722)$ & $<0.001$ \\
\hline \multicolumn{5}{|l|}{ Drug regimen } \\
\hline - Misoprostol & 1 & & & \\
\hline - Gemeprost & $0.710(0.401-1.258)$ & 0.241 & & \\
\hline Dinoprostone & 0 & 0.998 & & \\
\hline
\end{tabular}

study, we were able to show that the type of fetal abnormality which led to the termination had no effect on the duration of the abortion induction [8]. Due to conflicting results from other study groups, this aspect must be considered as not yet definitely resolved [12].

The shortest induction times were observed with the combined use of mifepristone with gemeprost or misoprostol. The combination of mifepristone and misoprostol has been licensed in France since 1988 [13]. The superiority of this combination over regimens which use dinoprostone or gemeprost had been confirmed in several studies, some randomised $[14,15]$. In a current Cochrane analysis, the use of misoprostol as a single agent was confirmed to be an effective method; however its combination with mifepristone appeared to significantly increase its effectiveness [7]. No mandatory guideline can currently be derived from the large number of randomised studies on dose, dosage interval and routes of administration which were included in this meta- analysis. Concerning the route of administration of misoprostol, Akoury et al. observed a significant advantage for vaginal administration with regard to induction time. In a controlled-randomised study using $400 \mu \mathrm{g}$ of misoprostol, they recorded an average induction time of $30.5( \pm 14.4)$ hours with oral and $18.3( \pm 8.2)$ hours with vaginal administration [16]. The vaginal administration of misoprostol at three-hourly intervals appears to be the most effective option with an acceptable side effect profile. The most frequently described side effect in this study was transient diarrhoea. Our chosen dosage of $400 \mu \mathrm{g}$ combined oral-vaginal administration every 4 to 6 hours starting 24-48 hours after mifepristone administration corresponds with the spectrum of treatment regimens to date and the recommendations of the AWMF's S1-guideline no. 015/031 [17,18]. Regarding the time interval between administration of mifepristone and misoprostol, a recent meta-analysis showed only moderate differences: the induction interval between the initial dose of misoprostol 
and delivery was only 1-2 hours shorter when mifepristone was used 12-24 hours before compared to a 36-48 hours interval [19]. Therefore, in a clinical setting, the start of prostaglandin administration within 24 hours of mifepristone administration appears to be most favourable, as the total duration of the abortion is effectively reduced and the variance of the possible abortion duration is limited to the greatest extent.

\section{Summary}

$\nabla$

In this study, we were able to show that mifepristone followed by misoprostol or gemeprost 24 to 48 hours later led to the most rapid abortions in the 2 nd and 3rd trimesters. In addition to the preliminary administration of mifepristone, gestational age and parity are significant influencing factors on the duration of induction.

\section{Conflict of Interest \\ $\nabla$}

None.

\section{References}

1 Segal SJ, LaGuardia KD. Termination of pregnancy - a global view. Baillieres Clin Obstet Gynaecol 1990; 4: 235-247

2 Statistisches Bundesamt. Schwangerschaftsabbrüche - Fachserie 12, Reihe 3 - 2012. Online: https://www.destatis.de/DE/ZahlenFakten/ GesellschaftStaat/Gesundheit/Schwangerschaftsabbrueche/ Schwangerschaftsabbrueche.html; last access: 04.11.2013

3 Esteve JL, Gallego FG, Llorente MP et al. Late second-trimester abortions induced with mifepristone, misoprostol and oxytocin: a report of 428 consecutive cases. Contraception 2008; 78: 52-60

4 Hammond $C$. Recent advances in second-trimester abortion: an evidence-based review. Am J Obstet Gynecol 2009; 200: 347-356

5 Bartlett LA, Berg CJ, Shulman HB et al. Risk factors for legal induced abortion-related mortality in the United States. Obstet Gynecol 2004; 103: 729-737
6 von Hertzen H, Piaggio G, Wojdyla D et al. Comparison of vaginal and sublingual misoprostol for second trimester abortion: randomized controlled equivalence trial. Hum Reprod 2009; 24: 106-112

7 Wildschut H, Both MI, Medema S et al. Medical methods for mid-trimester termination of pregnancy. Cochrane Database Syst Rev 2011; 1 : CD005216

8 Wagner $N$, Abele H, Hoopmann $M$ et al. Factors influencing the duration of late first and second-trimester termination of pregnancy with prostaglandin derivates. Eur J Obstet Gynecol Reprod Biol 2011; 155: 75-78

9 Dickinson JE, Doherty DA. Factors influencing the duration of pregnancy termination with vaginal misoprostol for fetal abnormality. Prenat Diagn 2009; 29: 520-524

10 Borgatta L, Kapp N. Clinical guidelines. Labor induction abortion in the second trimester. Contraception 2011; 84: 4-18

11 Jannet D, Aflak N, Abankwa A et al. Termination of 2nd and 3rd trimester pregnancies with mifepristone and misoprostol. Eur J Obstet Gynecol Reprod Biol 1996; 70: 159-163

12 Nesbitt $D$, Giles $W$. Prolonged induction to delivery time in termination of pregnancy using 16, 16-dimethyl-PGE1-methyl ester (gemeprost) for fetuses with a neural tube defect or hydrocephalus. Aust N Z J Obstet Gynaecol 1996; 36: 300-303

13 Fiala C. Induzierter Abort. medikamentöser Schwangerschaftsabbruch. Geburtsh Frauenheilk 2012; 71: 24-26

14 Bartley J, Baird DT. A randomised study of misoprostol and gemeprost in combination with mifepristone for induction of abortion in the second trimester of pregnancy. BJOG 2002; 109: 1290-1294

15 Wong KS, Ngai CS, Chan KS et al. Termination of second trimester pregnancy with gemeprost and misoprostol: a randomized double-blind placebo-controlled trial. Contraception 1996; 54: 23-25

16 Akoury HA, Hannah ME, Chitayat D et al. Randomized controlled trial of misoprostol for second-trimester pregnancy termination associated with fetal malformation. Am J Obstet Gynecol 2004; 190: 755-762

17 Ngoc NT, Shochet T, Raghavan S et al. Mifepristone and misoprostol compared with misoprostol alone for second-trimester abortion: a randomized controlled trial. Obstet Gynecol 2011; 118: 601-608

18 Tschudin S, Zanotelli D, Bitzer J et al. Experiences with medical abortion, in particular postabortion control, treatment in case of residuals and subsequent contraception. Geburtsh Frauenheilk 2004; 64: 12991304

19 Shaw KA, Topp NJ, Shaw JG et al. Mifepristone-misoprostol dosing interval and effect on induction abortion times: a systematic review. Obstet Gynecol 2013; 121: 1335-1347 